First publ. in: Applied Catalysis A 224 (2002), pp. 63-75

\title{
Preparation of isospecific metallocene catalysts for olefin polymerization that are covalently tethered on solid surface
}

\author{
Noriyuki Suzuki $^{\mathrm{a}, *}$, Jian Yu $^{\mathrm{a}, 1}$, Nobuyuki Shioda ${ }^{\mathrm{b}}$, Hayato Asami ${ }^{\mathrm{b}}$, \\ Takashi Nakamura ${ }^{\mathrm{a}}$, Thomas Huhn ${ }^{\mathrm{a}}$, Atsushi Fukuoka ${ }^{\mathrm{c}}$, Masaru Ichikawa ${ }^{\mathrm{c}}$, \\ Masahiko Saburi ${ }^{\mathrm{b}}$, Yasuo Wakatsuki ${ }^{\mathrm{a}}$

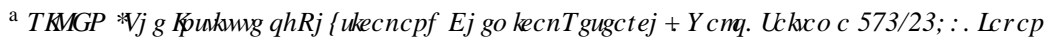

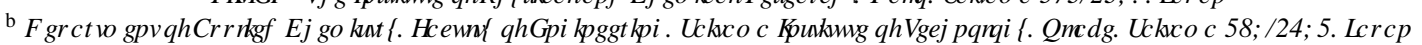

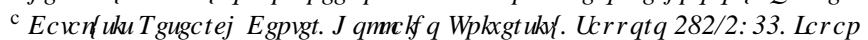

\section{\$ EWMDW}

Novel methodology was developed for preparation of isospecific metallocene catalysts for olefin polymerization that are tethered on silica surfaces with covalent bonds. A racemic DQMDirconocene complex that has a Si-Cl moiety on its bridge was immobilized on $\mathrm{SiO}_{2}$ by the reaction of the $\mathrm{Si}-\mathrm{Cl}$ anchor with $\mathrm{Si}-\mathrm{OH}$ on the solid surface. The prepared solid catalyst was found to be effective for isospecific propene polymerization (catalyst \$ ). Pretreatment of silica surfaces with $\mathrm{Me} \mathrm{S}_{3} \mathrm{SiCl}$ improved the catalyst performance (catalyst \%. An DQDDirconocene complex with a BH group reacted with "vinyl-coated" silica gel to afford another immobilized catalysts (catalyst $\boldsymbol{\&}$ ). This catalyst achieved satisfactorily high catalytic activity and high isotacticity in its produced polypropene. (c) 2002 Elsevier Science B.V. All rights reserved.

. HZRLGW Olefin polymerization catalyst; Metallocene; Silica support; Covalent bond

\section{QT , QMRGXFWRQ}

The group 4 metallocene catalysts for olefin polymerization have been extensively investigated over the last few decades [1-3]. Heterogenization of the metallocene catalysts is of much interest recently, since it is desired for industrial application [4,5]. Adsorption of the metallocene catalysts on the methylaluminoxane(MAO)-treated surface of solid supports is the commonly adopted method. In this method, however, leaching out during polymerization

\footnotetext{
* Corresponding author. Fax: +81-48-462-4665.

( $\square$ P DODOGH $\square$ nsuzuki@ postman.riken.go.jp (N. Suzuki).

${ }^{1}$ On leave from Shanghai Institute of Ceramics, Chinese Academy of Sciences (2000).
}

was pointed out [6], and since the adsorption method seems to highly depend on supports and metallocene complexes, it often suffers poor reproducibility. On the other hand, some examples for immobilization of metallocene complexes with covalent bonds on supports, such as polystyrene [7,8], silica gel [9-11] and polysiloxane $[12,13]$, have been reported. In most of such examples, ligands were tethered on supports first, and then $\mathrm{ZrCl}_{4}$ was reacted to form immobilized metallocene complexes (method (a) in Fig. 1), and a few of them could even catalyze syndiospecific olefin polymerization $[8,13]$. However, this is not suitable for preparation of LRISHEL polymerization catalysts because this method cannot avoid formation of PHR-isomers of metallocene complexes and their purification to obtain pure-racemic ones seems difficult. 
a) complexation onto a tethered ligand

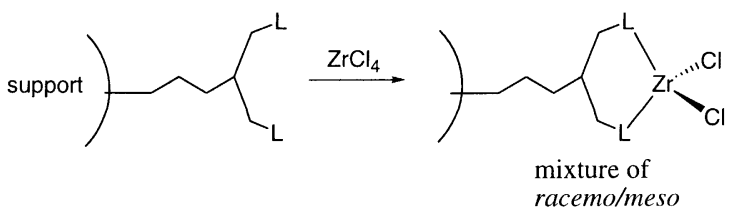

b) tethering a racemic complex with an anchor

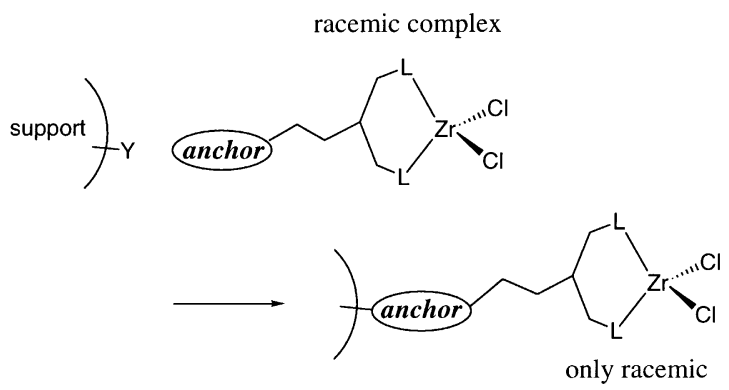

Fig. 1. Preparative methods for covalently tethered metallocenes on a support.

Hong et al. reported preparation of $W F H$ R-rich zirconocene catalysts from purely 'racemic' ligands that were tethered on polysiloxanes, although their reaction with metal chlorides gave a considerable amount of PHR-isomers [7]. Therefore, the catalysts immobilized by method (a) must produce a mixture of atactic and isotactic polymers, and extraction of atactic portion is needed in order to obtain isotactic polymers.

For preparation of covalently immobilized isospecific catalysts, to tether well-defined racemic metallocene complexes onto the support with anchors appears to be the only route (method (b) in Fig. 1). Tethering non-bridged DSHFIL zirconocene compounds with a cyclopentadienyl [14] or siloxy [15] anchor on $\mathrm{SiO}_{2}$ has been reported. Alt and coworkers reported metallocenes with vinyl groups which are incorporated in the polyethylene chain by copolymerization [16-18]. To the best of our knowledge, however, isospecific metallocene complexes chemically anchored on solid supports have not appeared in the literature [19]. ${ }^{2}$ A major barrier to achieve

\footnotetext{
${ }^{2}$ Immobilization of isospecific DQM-metallocenes with a $\mathrm{Si}-\mathrm{Cl}$ anchor on $\mathrm{SiO}_{2}$ was reported in a patent but without an experimental description of isospecific olefin polymerization.
}

this aim seems to be the difficulty of preparation of racemic complexes with an anchor moiety.

We recently reported preparation of the DQM zirconocene complex with a vinyl group on its silylene-bridge $\square$ that serves as an isospecific olefin polymerization catalyst [20]. The advantage of this complex is ease of purification of its racemic form. This compound led us to design racemic DQM zirconocenes functionalized on that vinyl group. Herein we wish to report the synthesis of isospecific silylene-bridged metallocene complexes that have $\mathrm{Si}-\mathrm{Cl}$ or $\mathrm{B}-\mathrm{H}$ functionality as anchoring moieties and their immobilization on silica surfaces (Fig. 2). This is the first example of isospecific olefin polymerization using racemic metallocene catalysts that are covalently immobilized on solid supports. A part of this work was previously communicated [21].

\section{Q 5 HXOVDQG GWXXWRQ}

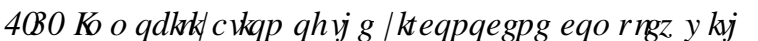 $D 6 I+\& O D Q F K R U R Q D$ YGFD WXUDFHDFDWDOWA}

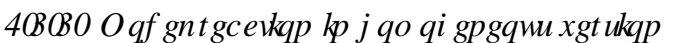

The racemic silylene-bridged zirconocene complex with a vinyl group $[(W F P R / P H R>99 / 1)$ reacted with chlorodimethylsilane $\left(\mathrm{Me}_{2} \mathrm{SiHCl}\right)$ in the presence of $\mathrm{H}_{2} \mathrm{PtCl}_{6}$ to afford the hydrosilated product $\square$ with excellent regioselectivity (Scheme 1). Compound $\square$ was fully characterized by ${ }^{1} \mathrm{H},{ }^{13} \mathrm{C}$ and ${ }^{29} \mathrm{Si}$ NMR spectroscopy. A possible regioisomer was not observed by NMR. Since a chlorodimethylsilyl group is known to be reactive enough, complex $\square$ can be expected to serve as a racemic zirconocene with a functional anchor moiety.
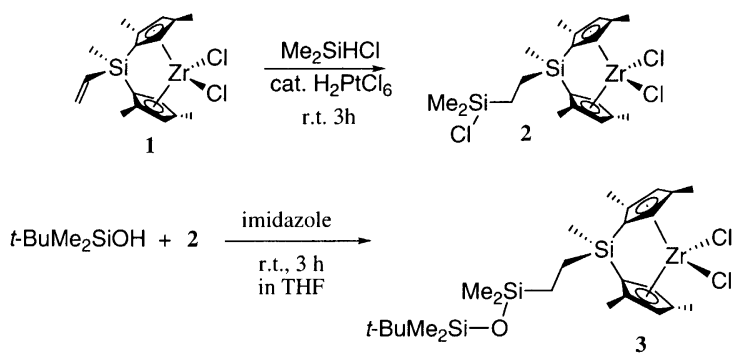

Scheme 1. Hydrosilation of DQM-zirconocene with a vinyl group. 


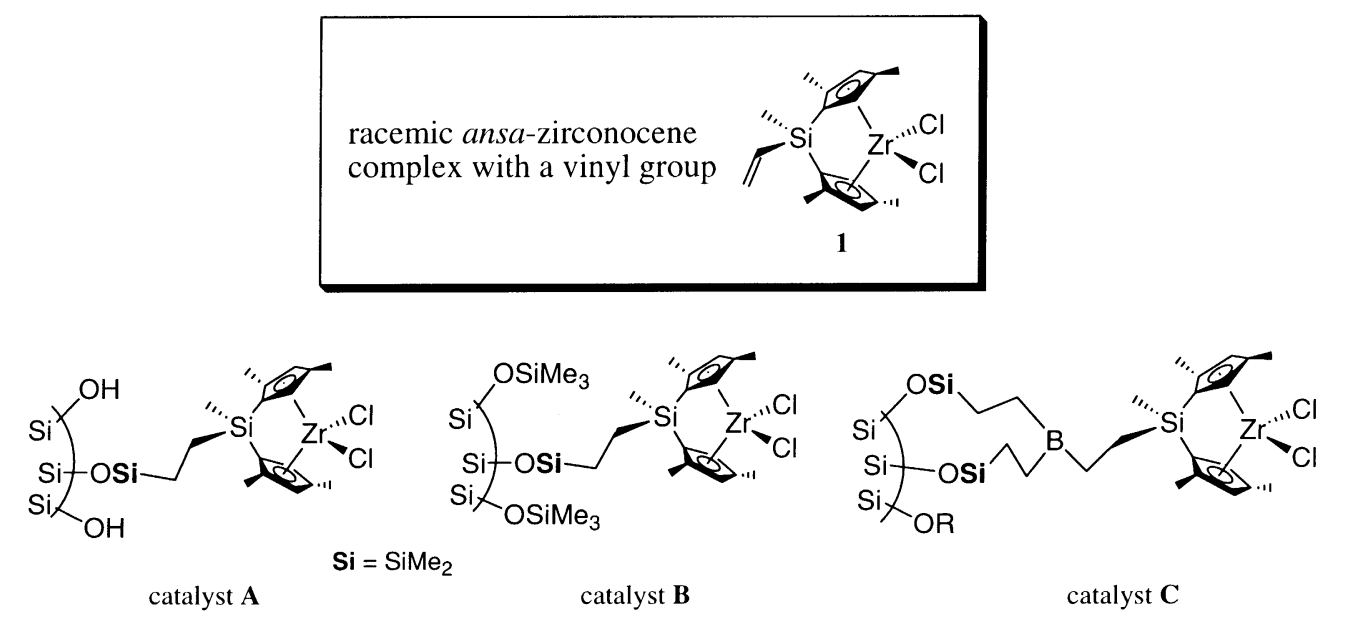

Fig. 2. Covalently immobilized isospecific metallocene catalysts.

We first examined the formation of $\mathrm{Si}-\mathrm{O}-\mathrm{Si}$ bonds in a homogeneous reaction of $\square$ with a silyl alcohol. When $\square$ was treated with 1 eq. of $\mathrm{ABuMe}_{2} \mathrm{SiOH}$ in the presence of imidazole in THF at RT, the formation of $\square$ was observed in an excellent yield after $3 \mathrm{~h} .{ }^{29} \mathrm{Si} \mathrm{NMR}$ spectroscopy showed disappearance of the $\mathrm{Si}-\mathrm{Cl}$ bond (32.65 ppm) of $\square$ and formation of new $\mathrm{Si}-\mathrm{O}-\mathrm{Si}$ bonds (7.94, $11.18 \mathrm{ppm})$, indicating that $\mathrm{Si}-\mathrm{OH}$ reacted predominantly with $\mathrm{Si}-\mathrm{Cl}$ instead of $\mathrm{Zr}-\mathrm{Cl}$ (Fig. 3).

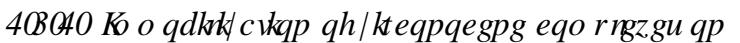

\section{$6 I 2_{2}$ ZIKK UIR[DQHERQGV SUSDUDRQRI FDUDOWA}

Thus, we next investigated the immobilization of $\square$ on silica by its reaction with surface $\mathrm{Si}-\mathrm{OH}$ groups (Scheme 2). Compound $\square$ was treated with calcined silica gel in toluene or tetrahydrofuran (THF) in the presence of bases. Two kinds of silica were used (I and II, in Table 1). CP/MAS high-resolution solid-state ${ }^{29} \mathrm{Si} \mathrm{NMR}$ spectra of the obtained solid catalyst is shown in Fig. 3. A broad signal at $14-17 \mathrm{ppm}$ and a sharp one at $-10.6 \mathrm{ppm}$ are assignable to $\mathrm{O}-\mathrm{SiMe}_{2} \mathrm{CH}_{2}-$ of the backside

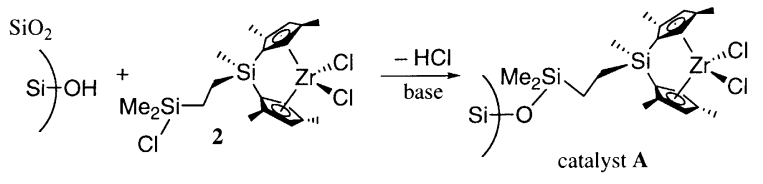

Scheme 2. Immobilization of the racemic zirconocene $\mathrm{Q}$. anchor and the metallocene-bridging silicon, respectively, and the signal for $\mathrm{Si}-\mathrm{Cl}$ of $\square$ at $32.7 \mathrm{ppm}$ disappeared. IR spectroscopy showed a decrease of $\mathrm{Si}-\mathrm{OH}$ on $\mathrm{SiO}_{2}\left(3750 \mathrm{~cm}^{-1}\right)$ due to the immobilization of $\square$ on the silica. These results supported the expected immobilization of complex $\square$ on $\mathrm{SiO}_{2}$. The $\mathrm{Zr}$ content in the prepared catalysts was determined by ICP analysis (Table 1). Catalysts prepared with toluene/triethylamine (runs 2-5) contained more $\mathrm{Zr}$ than that from THF/imidazole (run 1). For comparison, $\square$ was adsorbed on the silica surface similarly without a base and studied as a reference (runs 6 and 7).

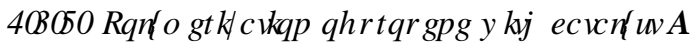

Polymerization of propene was carried out by suspending the immobilized catalysts in a toluene solution of propene and methylaluminoxane (MAO). Table 1 summarizes the results of polymerization. The catalysts based on $\square$ (catalyst \$) produced isotactic polypropene in moderate catalytic activity (runs 1-5), although the catalytic activities were much lower compared to the corresponding homogeneous catalyst $\square$ (run 8). It should be noted that the catalyst prepared with $\square$ as a reference showed much less catalytic activity than catalyst $\mathbf{\$}$, in spite of its similar $\mathrm{Zr}$ content (runs 6 and 7). This is probably because the $\mathrm{Zr}-\mathrm{Cl}$ bonds of $\mathrm{I}$ reacted with $\mathrm{Si}-\mathrm{OH}$ on the silica surfaces. When the amount of MAO was reduced from 2500 to 120 eq. of $\mathrm{Al} / \mathrm{Zr}$, the catalytic activity was $82 \mathrm{~kg} \mathrm{PP} / \mathrm{mol} \mathrm{Zrhatm} \mathrm{(run} \mathrm{4),} \mathrm{which} \mathrm{is} \mathrm{still}$ 
Table 1

Catalysts with immobilized zirconocene complexes (catalyst $\mathbf{A}$ ) and polymerization of propene ${ }^{\mathrm{a}}$

\begin{tabular}{|c|c|c|c|c|c|c|c|c|c|c|c|c|}
\hline Run & Catalyst & $\begin{array}{l}\text { Complex } \\
\text { (base) }\end{array}$ & Silica gel & Solvent ${ }^{\mathrm{b}}$ & $\begin{array}{l}\text { Zr-atom } \\
\text { (wt.\%) }\end{array}$ & $\begin{array}{l}\mathrm{MAO} \\
\mathrm{Al} / \mathrm{Zr}\end{array}$ & $\begin{array}{l}\text { PP yield } \\
(\mathrm{g})\end{array}$ & $\begin{array}{l}\text { Catalytic } \\
\text { activity }^{\mathrm{c}}\end{array}$ & $M_{\mathrm{W}}$ & $M_{\mathrm{w}} / M_{\mathrm{n}}$ & $\begin{array}{l}{[\mathrm{mmmm}]} \\
(\%)\end{array}$ & $\begin{array}{l}\mathrm{mp} \\
\left({ }^{\circ} \mathrm{C}\right)\end{array}$ \\
\hline 1 & $\mathbf{A}$ & 2/imidazole & $\mathrm{I}^{\mathrm{d}}$ & THF & 0.47 & 3900 & 0.525 & 113 & 106000 & 2.59 & 91.1 & 151.0 \\
\hline 2 & $\mathbf{A}$ & $2 / \mathrm{Et}_{3} \mathrm{~N}$ & I & Toluene & 0.75 & 2400 & 0.796 & 108 & 94000 & 2.45 & 87.7 & 150.8 \\
\hline 3 & $\mathbf{A}$ & & & & & 600 & 0.755 & 101 & 91900 & 2.33 & 87.5 & 149.7 \\
\hline 4 & A & & & & & 120 & 0.605 & 81 & 106000 & 2.24 & - & 152.3 \\
\hline 5 & $\mathbf{A}$ & $2 / \mathrm{Et}_{3} \mathrm{~N}$ & $\mathrm{II}^{\mathrm{e}}$ & Toluene & 0.78 & 2300 & 0.641 & 83 & 74500 & 2.87 & 86.9 & 146.1 \\
\hline 6 & Ref. & 1/none & I & Toluene & 0.79 & 2300 & 0.073 & 9.4 & 65100 & 1.85 & 92.4 & 156.0 \\
\hline 7 & Ref. & 1/none & II & Toluene & 0.76 & 2400 & 0.137 & 18 & 106000 & 2.06 & 93.2 & 159.0 \\
\hline 8 & Ref. & 1 & & Homogeneous ${ }^{\mathrm{f}}$ & & 5000 & 2.35 & 7840 & 76500 & 1.99 & 95.7 & 157.1 \\
\hline
\end{tabular}

${ }^{a}$ Reaction conditions: in a $100 \mathrm{ml}$ autoclave, toluene $30 \mathrm{ml}$, catalyst $30 \mathrm{mg}$, propene $3 \mathrm{~atm}, 30^{\circ} \mathrm{C}, 1 \mathrm{~h}$.

${ }^{\mathrm{b}}$ Solvents for immobilization reactions.

${ }^{c} \mathrm{~kg} \mathrm{PP} / \mathrm{mol} \mathrm{Zrhatm}$.

dI: Degussa corporation "Aerosil 300": $300 \mathrm{~m}^{2} / \mathrm{g}$.

e II: Fuji Silysia Chemical Ltd. "CARiACT P-10": $281 \mathrm{~m}^{2} / \mathrm{g}$.

${ }^{\mathrm{f}} \mathrm{Zr}=0.1 \mu \mathrm{mol}$. 
(a) complex 2

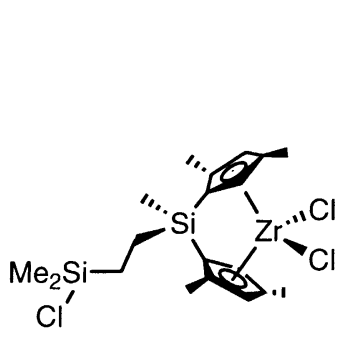

$\mathrm{Me}_{4} \mathrm{Si}$
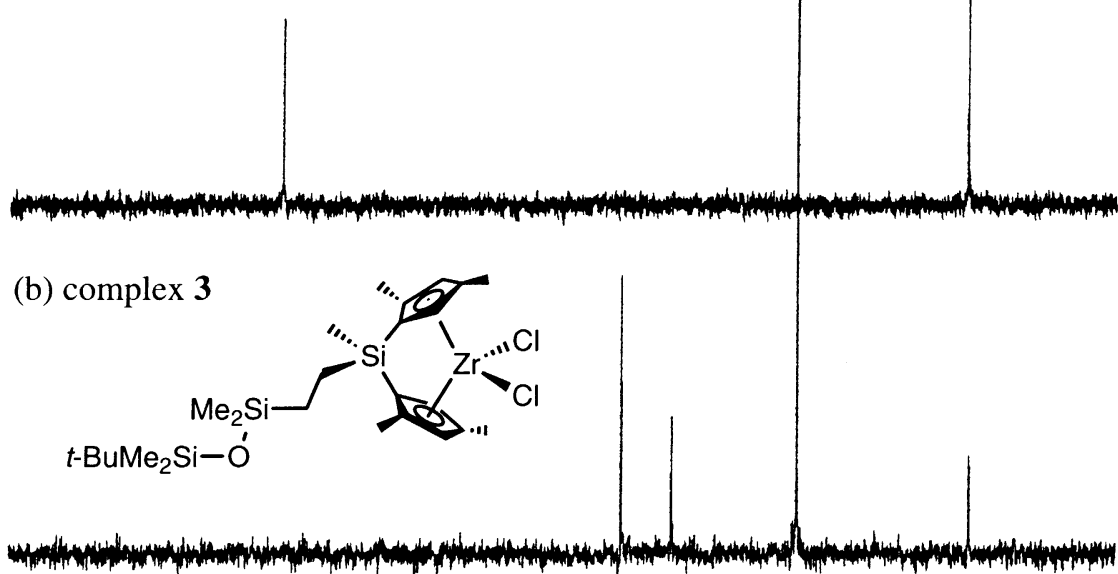

(c) catalyst A

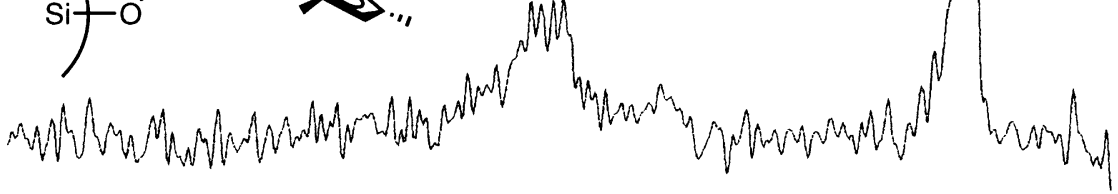

PPM

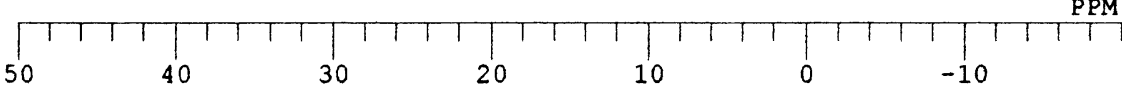

Fig. $3 .{ }^{29} \mathrm{Si}$ NMR spectra for $\square, \square$ and immobilized catalyst \$ .

comparable to that of run 2. It was reported that supported catalysts require less amount of MAO to achieve high activity $[22,23]$. Isotacticity of the polymers was determined using the obtained polymers without extraction of an atactic portion. The percentage of $P H R$-pentad ([PPPP]), which is an index of isotacticity of the polymer, was satisfactory. However, both $[P P P P]$ and melting point were slightly lower than those observed in the homogeneous reaction. Similar results were obtained with two kinds of silica supports (I and II), indicating the reproducibility of this method.

These results revealed that immobilization of racemic DQMmetallocene with a $\mathrm{Si}-\mathrm{Cl}$ anchor is effective. Their catalytic activities, however, were not satisfactory when compared to homogeneous reactions. A possible reason could be the presence of excess hydroxy groups on the silica surface, compared to the amount of zirconium used. It was reported that, in general, silica treated under vacuum at $500^{\circ} \mathrm{C}$ 


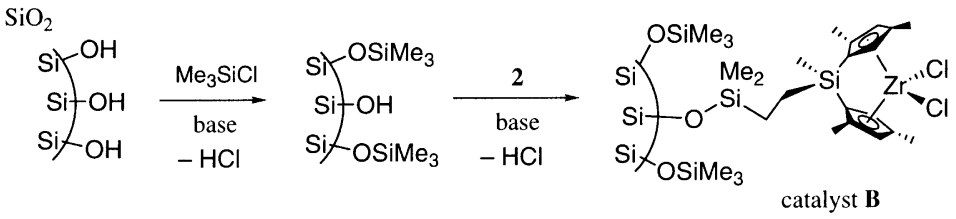

Scheme 3. Masking excess $\mathrm{OH}$ groups.

Table 2

Pretreatment of $\mathrm{SiO}_{2}$ with $\mathrm{Me}_{3} \mathrm{SiCl}$ : polymerization of propene with catalyst $\mathbf{\%}$

\begin{tabular}{rllllllll}
\hline Run & $\begin{array}{l}\mathrm{Me}_{3} \mathrm{SiCl}^{\mathrm{b}} \\
\left(\mathrm{mmol}^{-1}\right.\end{array}$ & $\begin{array}{l}\mathrm{Zr} \text {-atom } \\
(\mathrm{wt} . \%)\end{array}$ & $\begin{array}{l}\text { Catalyst } \\
(\mathrm{mg})\end{array}$ & $\begin{array}{l}\text { PP yield } \\
(\mathrm{g})\end{array}$ & $\begin{array}{l}\text { Catalytic } \\
\text { activity }\end{array}$ & $0_{\mathrm{w}}$ & $0_{\mathrm{w}} / 0_{\mathrm{n}}$ & {$[P P P P]$} \\
\hline 5 & 0 & 0.78 & 30 & 0.64 & 83 & 74500 & 2.87 \\
9 & 0.3 & 0.74 & 30 & 0.88 & 121 & 71000 & 2.34 & 84.9 \\
10 & 0.9 & 0.47 & 15 & 2.03 & 876 & 98600 & 2.60 & 86.8 \\
11 & 1.8 & 0.13 & 30 & 0.46 & 359 & 91900 & 2.42 \\
\hline
\end{tabular}

${ }^{\text {a }}$ Reaction conditions: silica gel $=\mathrm{II}, \mathrm{MMAO}: \mathrm{Al}=2 \mathrm{mmol} / 10 \mathrm{mg}$ of catalyst, toluene $=30 \mathrm{ml}$, propene $=3 \mathrm{~atm}, 30^{\circ} \mathrm{C}, 1 \mathrm{~h}$.

${ }^{\mathrm{b}} \mathrm{mmol}$ of $\mathrm{Me}_{3} \mathrm{SiCl} / 1 \mathrm{~g}$ of $\mathrm{SiO}_{2}$.

${ }^{\mathrm{c}} \mathrm{kg} \mathrm{PP/mol} \mathrm{Zrhatm.}$

contains about two $\mathrm{OH}$ groups on $1 \mathrm{~nm}^{2}$ of its surface [24]. This corresponds to ca. $1 \mathrm{mmol}$ of $\mathrm{OH}$ groups in $1 \mathrm{~g}$ of the silica used here, while $0.1 \mathrm{mmol}$ of $\mathrm{Zr}$ was used for tethering on $1 \mathrm{~g}$ of $\mathrm{SiO}_{2}$. These excess hydroxy groups might damage the active species.

\section{पQI ,P SURYH HQWRI FDWDOWF SHURLP DQFHE $P$ DUNQJ KI GR[। JURXSVRQ WKH UCFD WUUDFH $\square F D W D W B \square$}

We reasoned that masking a part of surface-OH groups with trimethylsilyl groups would improve the activity of the catalyst (Scheme 3) [25]. ${ }^{3}$ A silica support was pretreated with chlorotrimethylsilane, $\mathrm{Me}_{3} \mathrm{SiCl}$, in order to convert $-\mathrm{OH}$ groups on the surface into $-\mathrm{OSiMe}_{3}$ groups. Assuming that $1 \mathrm{~g}$ of silica has about $1.0 \mathrm{mmol}$ of hydroxy groups, the amount of the masking agent was made to vary from 0.3 to $1.8 \mathrm{mmol}$ per $1 \mathrm{~g}$ of silica gel. Pretreated silica was washed and dried, and then compound $\square$ was immobilized similarly to catalyst $\mathbf{\$}$. Zr-contents of the obtained solid (catalyst $\%$ were smaller than catalyst $\$$ when more than $0.9 \mathrm{mmol} / \mathrm{g} \mathrm{SiO}_{2}$ of $\mathrm{Me}_{3} \mathrm{SiCl}$

\footnotetext{
${ }^{3}$ Pretreatment of $\mathrm{SiO}_{2}$ with $\mathrm{Me}_{3} \mathrm{SiCl}$ for silica-supported zirconocene was reported.
}

was used. Table 2 summarizes the results of propene polymerization using catalyst \% Catalyst \% showed remarkably improved catalytic activity in propene polymerization. The yield of the polymer increased even though the amount of $\mathrm{Zr}$-atom was smaller. Pretreatment with $0.9 \mathrm{mmol} / \mathrm{g} \mathrm{SiO}_{2}$ of $\mathrm{Me}_{3} \mathrm{SiCl}$ gave the highest activity (run 10). Treatment with excess $\mathrm{Me}_{3} \mathrm{SiCl}$ resulted in a decrease of $\mathrm{Zr}$ on the surface and a polymer yield as expected (run 11). Isotacticity of the polymer, however, remains lower, while the catalytic activity was improved by this masking method. Although the reason for the low isotacticity in the present system is not clear yet, it may be because the active species stay too close to the solid surface. Thus, we designed further study on tethering the complex with a longer spacer to improve this method (Section 2.3).

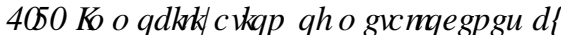 $K I$ GRERLURQ RQ YIQ QUUG WXUDFH}

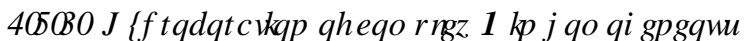 VROURQ}

Hydroboration of alkenes is one of the most versatile reactions in organic synthesis. We considered that this reaction could be applied for immobilization 

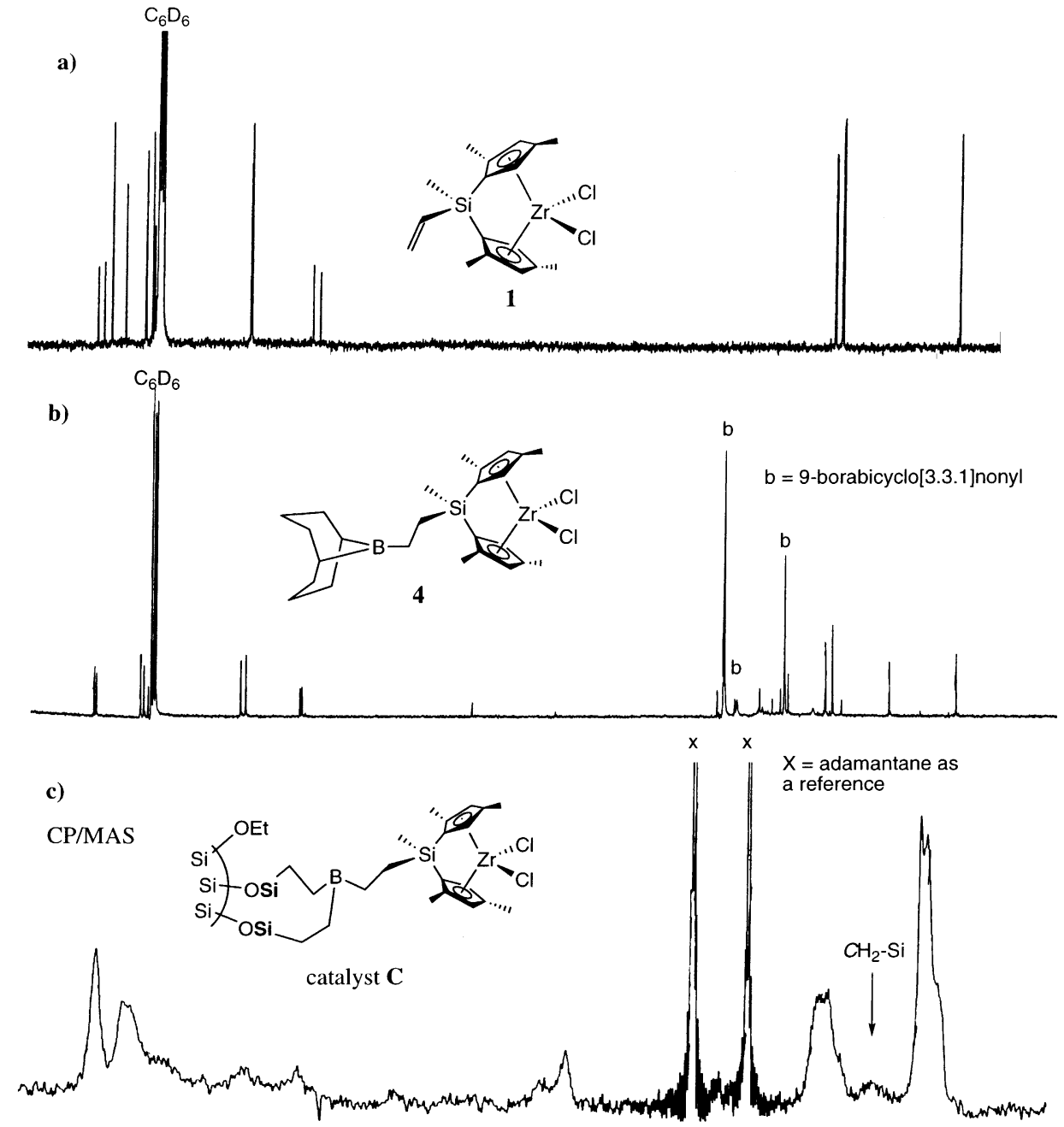

d)

\section{CP/MAS}

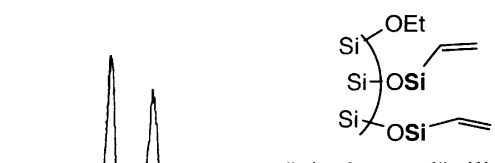

"vinyl-coated" silica gel

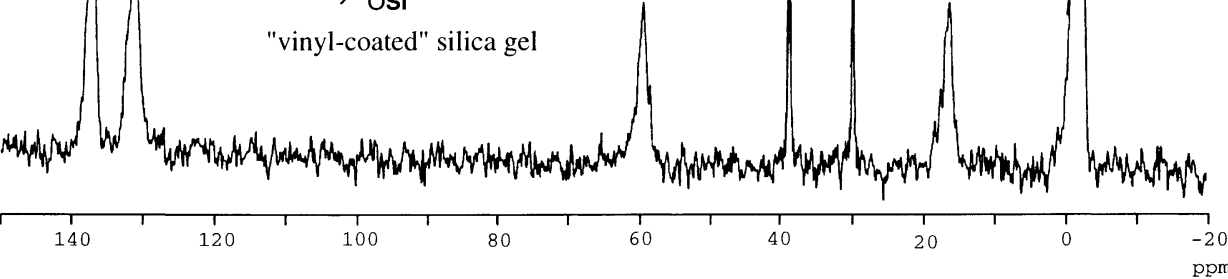

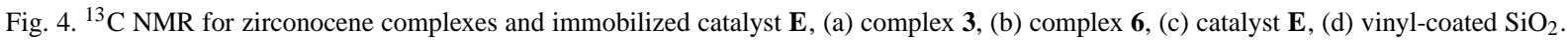



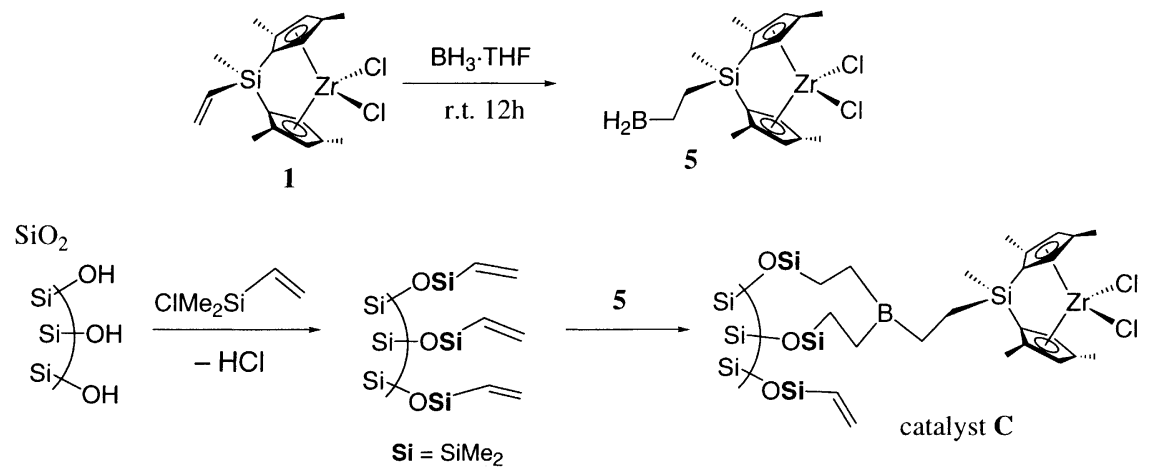

Scheme 4. Immobilization of metallocenes by hydroboration.

of metallocene complexes [26]. ${ }^{4}$ We first tested the hydroboration reaction of $\square$ (Eq. (1)) with 9-borabicyclo[3.3.1.]nonane (9-BBN), a common hydroborating reagent. When $\square$ reacted with 1.5 eq. of 9-BBN, hydroboration cleanly proceeded in $15 \mathrm{~h}$ at $50{ }^{\circ} \mathrm{C}$ to give $\square$ in a good yield. ${ }^{13} \mathrm{C}$ NMR spectra of $\square$ and $\square$ are shown in Fig. 4. The vinyl groups of $\square$ at 133.73 and $135.98 \mathrm{ppm}$ disappeared and new methylene signals for $-\mathrm{BCH}_{2} \mathrm{CH}_{2} \mathrm{Si}$ - were observed at 18.89 and $6.53 \mathrm{ppm}$ accompanied with three signals assignable to the borabicyclo moiety (spectrum E, Fig. 4). ${ }^{1} \mathrm{H}$ NMR also supported the structure of $\square$ and signals for a regioisomer were not detected. The combination of $\square$ with MAO catalyzed propene polymerization to give highly isotactic polypropene, indicating that the zirconocene moiety survived the hydroboration reaction.
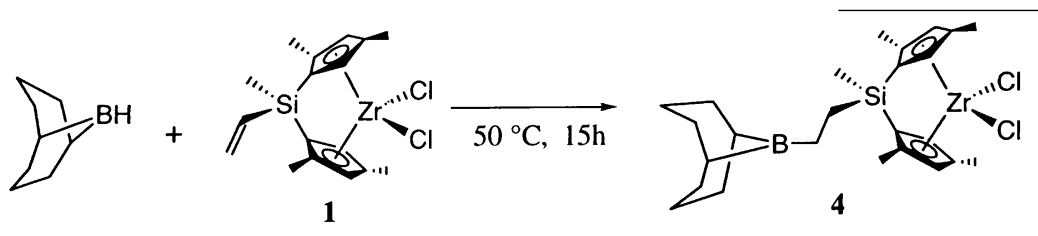

\section{पषप 3 USDWWRQ RI IP P REID]HG FDWDWEI}

\section{KI GRERLURQ}

These results encouraged us to investigate the immobilization of $\square$ by hydroboration reactions (Scheme 4). Silica gel was treated with excess chlorodimethylvinylsilane, $\mathrm{ClSiMe}_{2}\left(\mathrm{CH}=\mathrm{CH}_{2}\right)$, in

\footnotetext{
$\overline{{ }^{4} \text { Hydroboration of vinylated silica surface has been reported }}$ recently.
}

ethanol or toluene in order to cover the surface with $-\mathrm{OSiMe}_{2}\left(\mathrm{CH}=\mathrm{CH}_{2}\right)$ groups. The signals of vinyl groups on the silica surface were observed at 131 and 138 ppm by CP/MAS high-resolution solid-state ${ }^{13} \mathrm{C}$ and $60 \mathrm{ppm}$ ) when ethanol was used as a solvent. All hydroxy groups on the surface must be masked by this procedure. Complex $\square$ was treated with a large excess of borane-tetrahydrofuran complex $\left(\mathrm{BH}_{3}\right.$.THF) in THF, and the volatile material was removed in vacuo. The vinyl group of $\square$ disappeared judging from NMR, although the hydroborated product $\square$ could not be identified by NMR. ${ }^{1} \mathrm{H}$ NMR spectroscopy of the hydroboration products showed a mixture of some species probably because of the dimerization of primary boranes $\left(\mathrm{RBH}_{2}\right)$ and the formation of by-products such as regioisomers and doubly hydroborated products. NMR (Fig. 4d). Ethoxy groups were also observed (17

4

Anyhow, this reaction mixture was treated with the "vinyl-coated" silica in a toluene suspension at RT and then stirred overnight. The solid was rinsed with toluene and dried in vacuo to give the immobilized catalyst (catalyst \&). CP/MAS solid-state ${ }^{13} \mathrm{C}$ NMR spectroscopy of the catalyst exhibited a broad signal at $9 \mathrm{ppm}$ assignable to $\mathrm{sp}^{3}$-methylene carbons adjacent to the silicon atoms and other signals which are due to the zirconocene complex, suggesting that the complex 

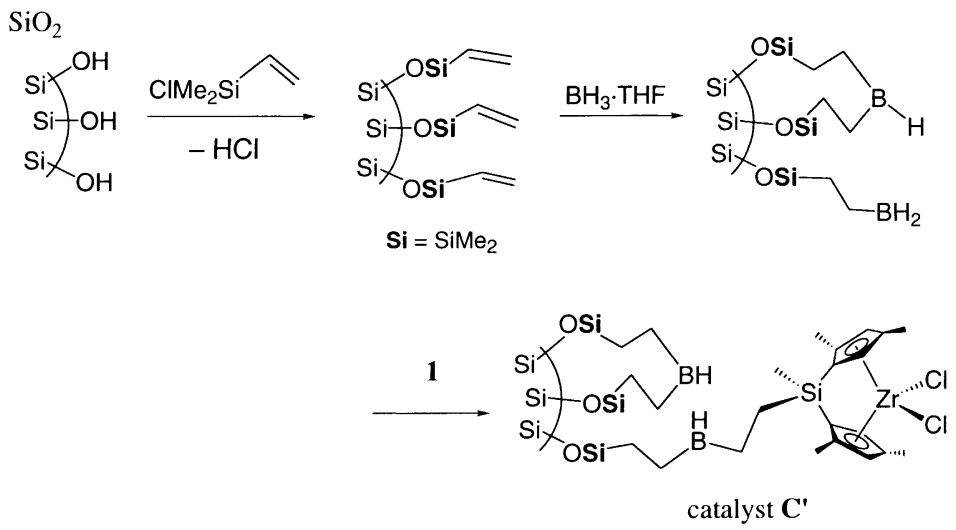

Scheme 5. An alternative method for immobilization of metallocenes.

was successfully immobilized (Fig. 4c). ICP analysis showed that the zirconium-contents of the catalysts were $0.34-0.36 \mathrm{wt} . \%$, indicating that about $30 \%$ of the complexes was loaded. The low efficiency of loading may be due to isomeric by-products in the first hydroboration.

We also prepared another catalyst by an alternative approach. The "vinyl-coated" silica surface was treated with $\mathrm{BH}_{3}$ first, then with the vinyl complex $\square$ (catalyst \&', Scheme 5). Catalyst \&' contained only 0.15 wt. $\%$ of $\mathrm{Zr}$, and it was even smaller than catalyst \&. This might be due to deficiency of $\mathrm{BH}$ moieties because $\mathrm{BH}_{3}$ immediately reacted with three vinyl groups to afford trialkylboranes on the surface.

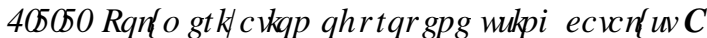

Table 3 summarizes the results of propene polymerization using catalyst $\boldsymbol{\&}$ and gives a comparison with the results for catalysts $\$$ and $\%$ It should be emphasized that the novel catalyst \& exhibited significantly higher catalytic activity than $\$$ or $\%$ When the ratio $\mathrm{Al} / \mathrm{Zr}$ was 2000 (runs 12 and 15), the activity of \& $(946 \mathrm{~kg} \mathrm{PP} / \mathrm{mol} \mathrm{Zrh}$ atm) was twice as high as that of $\%(504 \mathrm{~kg} \mathrm{PP} / \mathrm{mol} \mathrm{Zrh} \mathrm{atm})$. Catalytic activity amounted to $3500 \mathrm{~kg} \mathrm{PP} / \mathrm{mol} \mathrm{Zrh}$ atm when $\mathrm{Al} / \mathrm{Zr}$ was 5100 (run 14). Furthermore, isotacticity of the obtained polypropene with \& was much higher than those with $\$$ or $\%$ Observed PHR-pentad probability was more than $94 \%$ and it was comparable to the homogeneous catalyst, although catalytic activity was somewhat lower than the homogeneous one. High isotacticity of the polymers was also confirmed by their melting points. Catalyst $\&$ was prepared twice in the same manner (runs 13 and 14). These two catalysts showed the same $\mathrm{Zr}$-contents and exhibited similar results in polymerization, indicating the reproducibility

Table 3

Comparison of catalysts $\mathbf{\$}-\mathbf{\&}$ : polymerization of propene ${ }^{\mathrm{a}}$

\begin{tabular}{|c|c|c|c|c|c|c|c|c|c|c|}
\hline Run & Catalyst & $\begin{array}{l}\text { Zr-atom } \\
\text { (wt.\%) }\end{array}$ & $\begin{array}{l}\text { Catalyst } \\
(\mathrm{mg})\end{array}$ & $\mathrm{Al} / \mathrm{Zr}$ & PP yield (g) & $\begin{array}{l}\text { Catalytic } \\
\text { activity }^{\text {b }}\end{array}$ & $0_{\mathrm{w}}$ & $0_{\mathrm{w}} / 0_{\mathrm{n}}$ & {$[P P P P]$} & $\mathrm{mp}$ \\
\hline 5 & $\$$ & 0.78 & 30 & 2300 & 0.64 & 83 & 74500 & 2.87 & 86.9 & 146.1 \\
\hline 10 & $\%$ & 0.47 & 15 & 3900 & 2.03 & 879 & 98600 & 2.60 & 86.8 & 152.5 \\
\hline 12 & $\%$ & 0.47 & 10 & 2000 & 0.78 & 504 & 106000 & 2.61 & 86.3 & 153.5 \\
\hline 13 & $\&$ & 0.34 & 10 & 5400 & 2.64 & 2380 & 98900 & 1.49 & 94.1 & 156.2 \\
\hline 14 & $\&$ & 0.36 & 10 & 5100 & 4.18 & 3570 & 80900 & 1.46 & 94.7 & 154.5 \\
\hline 15 & $\&$ & 0.36 & 10 & 2000 & 1.12 & 946 & 112000 & 2.02 & 95.3 & 156.2 \\
\hline 16 & $\boldsymbol{\&}^{\prime}$ & 0.15 & 30 & 12000 & 1.38 & 917 & 99200 & 1.62 & 93.3 & 157.6 \\
\hline
\end{tabular}

${ }^{\text {a }}$ Reaction conditions: silica gel $=\mathrm{II}$, toluene $=30 \mathrm{ml}$, propene $=3 \mathrm{~atm}, 30^{\circ} \mathrm{C}, 1 \mathrm{~h}$.

${ }^{\mathrm{b}} \mathrm{kg} \mathrm{PP} / \mathrm{mol} \mathrm{Zrhatm}$. 
of this method. These results showed that the present methodology for tethering isospecific polymerization catalysts is extremely effective.

Catalyst $\boldsymbol{\&}^{\prime}$ exhibited lower activity than $\boldsymbol{\&}$ despite a higher $\mathrm{Al} / \mathrm{Zr}$ ratio (run 16 ). There would be an excess alkylboranes around $\mathrm{Zr}$ in this catalyst. Since $\mathrm{BR}_{3}$ groups have strong Lewis acidity, it may interact with a cationic active species to disturb the polymerization.

The excellent catalytic performance of this catalyst $\&$ could be ascribed to the following two points. First, pretreatment of each silica surface with excess chlorodimethylvinylsilane not only afforded 'vinyl'-surface for hydroboration, but also masked hydroxy groups effectively. Second, a spacer moiety is longer compared to catalysts $\$$ and $\%$ When a spacer is shorter, polymerization would occur near solid surfaces. It is possible that the solid surface disturbs the insertion reaction so as to decrease its activity and/or stereoselectivity. In catalyst \&, zirconocene complexes would catalyze the polymerization in locations distant from the solid surface because of the longer spacer. These complexes might behave in a nearly homogeneous fashion. Indeed, polymers produced by $\boldsymbol{\&}$ have smaller molecular weight distribution $\left(0_{\mathrm{w}} / M_{\mathrm{n}} \leq 2.0\right)$, while the values were larger than 2.0 in $\$$ and $\%$ This implies that the zirconocene complex in catalyst \& behaved like a single site catalyst.

The possibility of leaching out of loaded complexes was investigated according to the reported method [6]. Catalyst \& was suspended in a toluene solution of MAO and filtered. When the filtrate was exposed to propene ( $3 \mathrm{~atm})$, a trace of polymer was obtained. However, the yield was very low and the result suggested that only a few percent of the polymer was due to metallocene complexes that were leached out. The siloxane spacer might react with MAO, because the filtrate did not polymerize propene at all when catalyst \& was suspended in toluene ZLWKRXW MAO.

\section{पि \&RQFOYRQ}

In conclusion, we developed a novel methodology for preparation of covalently immobilized isospecific metallocene catalysts. Metallocene complexes were tethered on the support surface by siloxane formation (catalyst \$). The catalyst performance was improved by masking excess hydroxy groups on each solid surface (catalyst $\%$. Tethering complexes by hydroboration gave the most active catalysts (catalyst \&) and they produced highly isotactic polypropene.

\section{पि ( [ SHIP HQWDO}

\section{१ए० * HQHDO}

All manipulation was carried out under argon or nitrogen. Solvents were distilled over sodium benzophenoneketyl prior to use. Chlorodimethylsilane, WHAbutyldimethylsilanol, 9-borabicyclo[3.3.1]nonane (9-BBN, 0.4 M hexane solution) and $\mathrm{BH}_{3}$. THF (1.0 M THF solution) were purchased from Aldrich Chemical Co. Inc., and used without further purification. Complex $\square$ was prepared according to the reported method [20]. Silica gel ("Aerosil 300": $300 \mathrm{~m}^{2} / \mathrm{g}$ and "CARiACT P-10": $281 \mathrm{~m}^{2} / \mathrm{g}$ ) was provided from Degussa Corporation and Fuji Silysia Chemical Ltd., respectively, and was dried under vacuum $\left(10^{-3}\right.$ Torr, 1 Torr $\left.=133 \mathrm{~Pa}\right)$ at $500^{\circ} \mathrm{C}$ for $16 \mathrm{~h}$. Solution NMR was recorded on a JEOL AL300 spectrometer. All ${ }^{13} \mathrm{C}$ CP/MAS spectra were acquired at 100.3 MHz with a Chemagnetics Infinity $400 \mathrm{MHz}$ solid-state NMR spectrometer and were internally referenced to tetramethylsilane and the methine peak of adamantane $(29.5 \mathrm{ppm})$. The spectra were measured with $4.5 \mathrm{~ms}$ pulse width $\left(90^{\circ}\right.$ pulse), $3 \mathrm{~ms}$ contact time, $5 \mathrm{~s}$ pulse delay and 40,000 accumulations. The spinning was carried out at $5.0 \mathrm{kHz}$ spinning rate. All ${ }^{29} \mathrm{Si} \mathrm{CP} / \mathrm{MAS}$ spectra were obtained at $79.3 \mathrm{MHz}$ with a JEOL $\alpha-400$ NMR spectrometer with solid-state NMR attachments and were externally referenced to tetramethylsilane. The ${ }^{29} \mathrm{Si}$ spectra were measured with $6.0 \mu \mathrm{s}$ pulse width $\left(90^{\circ}\right.$ pulse), $3 \mathrm{~ms}$ contact time, $5 \mathrm{~s}$ pulse delay and 3000 accumulations. The spinning was carried out at $6.0 \mathrm{kHz}$ spinning rate. Gel permeation chromatography (GPC) was recorded on SSC-7100 high temperature GPC (Senshu Scientific Co. Ltd.) at $135^{\circ} \mathrm{C}$ using 1,2-dichlorobenzene as an eluent and monodispersed polystyrene as standards. The melting point of polypropene was determined by Rigaku DSC 8230. 


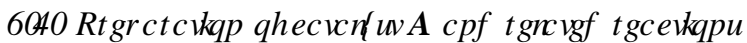

\section{पस⿴囗 + । GRUDURQRI 1 ZLK FKCRLRGP HKI QIDQH}

To a solution of $\square(34.2 \mathrm{mg}, 0.082 \mathrm{mmol})$ in diethyl ether $(1 \mathrm{ml})$ was added dimethylchlorosilane $(0.1 \mathrm{ml})$, and then a drop of THF solution of $\mathrm{H}_{2} \mathrm{PtCl}_{6}$ $(1 \mathrm{M})$ was added at RT. After the reaction mixture was stirred for $1 \mathrm{~h}$, the volatiles were removed in vacuo. ${ }^{1} \mathrm{H}$ NMR observation showed quantitative formation of the hydrosilation product $\square .{ }^{1} \mathrm{H}$ NMR $\left(\mathrm{C}_{6} \mathrm{D}_{6}, \mathrm{Me}_{4} \mathrm{Si}\right): \delta=0.24(\mathrm{~s}, 6 \mathrm{H}), 0.36(\mathrm{~s}, 3 \mathrm{H})$, 0.66-0.74 (m, 2H), 0.96-1.07 (m, 2H), 1.88 (s, 3H), $1.89(\mathrm{~s}, 3 \mathrm{H}), 2.27(\mathrm{~s}, 3 \mathrm{H}), 2.34(\mathrm{~s}, 3 \mathrm{H}), 5.06(\mathrm{~s}, 1 \mathrm{H})$, $5.10(\mathrm{~s}, 1 \mathrm{H}), 6.32(\mathrm{~s}, 1 \mathrm{H}), 6.34(\mathrm{~s}, 1 \mathrm{H}) .{ }^{13} \mathrm{C} \mathrm{NMR}$ $\left(\mathrm{C}_{6} \mathrm{D}_{6}, \mathrm{Me}_{4} \mathrm{Si}\right): \delta=-5.00\left(\mathrm{Si}-\& \mathrm{H}_{3}\right), 0.85,0.90$ $\left(\mathrm{ClSi}\left(\& \mathrm{H}_{3}\right)_{2}-\right), 5.58\left(\mathrm{Si}_{2}\right), 10.30\left(\mathrm{Si}_{2}\right), 15.74$, 15.82, 16.91, 16.97 (Cp0 H), 102.81, 103.31, 112.41, $113.41,127.52,128.93,129.44,130.29,137.56$, 138.28. ${ }^{29} \mathrm{Si} \mathrm{NMR}\left(\mathrm{C}_{6} \mathrm{D}_{6}, \mathrm{Me}_{4} \mathrm{Si}\right): \delta=-10.84$, 32.65 .

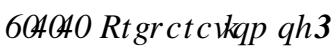

Complex $\square$ was prepared as described above and the volatiles were removed in vacuo. The residual solid was used for the reaction. Imidazole $(34 \mathrm{mg}$, $0.5 \mathrm{mmol})$ and dimethyl-WHAbutylsilanol $(78.8 \mathrm{ml}$, $0.5 \mathrm{mmol}$ ) was dissolved in $5 \mathrm{ml}$ of THF. A portion $(0.7 \mathrm{ml})$ of this solution was added to $\square(0.07 \mathrm{mmol})$ at RT. A white solid immediately precipitated from the reaction mixture and it was stirred for overnight. The formation of $\square$ was detected in ${ }^{29} \mathrm{Si}$ NMR and no other signals were observed. ${ }^{1} \mathrm{H}$ NMR $\left(\mathrm{C}_{6} \mathrm{D}_{6}\right.$, $\left.\mathrm{Me}_{4} \mathrm{Si}\right): \delta=0.06(\mathrm{~s}, 6 \mathrm{H}), 0.13(\mathrm{~s}, 6 \mathrm{H}), 0.44$ (s, $3 \mathrm{H}), 0.55-0.67$ (m, 2H), 0.93 (s, 9H), 1.04-1.11 (m, $2 \mathrm{H}), 1.88(\mathrm{~s}, 3 \mathrm{H}), 1.96(\mathrm{~s}, 3 \mathrm{H}), 2.25(\mathrm{~s}, 3 \mathrm{H}), 2.27(\mathrm{~s}$, $3 \mathrm{H}), 5.09,(\mathrm{~s}, 1 \mathrm{H}), 5.19(\mathrm{~s}, 1 \mathrm{H}), 7.16(\mathrm{~m}, 2 \mathrm{H}) .{ }^{13} \mathrm{C}$ NMR $\left(\mathrm{C}_{6} \mathrm{D}_{6}, \mathrm{Me}_{4} \mathrm{Si}\right): \delta=-4.90,-2.85,1.34,5.91$, $9.42,15.73$ (2C), 16.94 (2C), 18.22, 25.83, 103.09, $103.66,112.31,113.26,129.30,129.91,133.53$, 135.76, 137.38, 137.84. ${ }^{29} \mathrm{Si}$ NMR $\left(\mathrm{C}_{6} \mathrm{D}_{6}, \mathrm{Me}_{4} \mathrm{Si}\right)$ : $\delta=-10.87,7.94,11.18$.

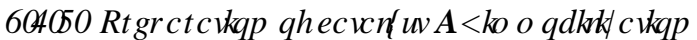 RI 2 RQ UQFD XUDFH}

The typical procedure for the preparation of catalyst \$ was as follows. Dry silica gel $(0.5 \mathrm{~g})$ was suspended in dry tetrahydrofuran (THF, $10 \mathrm{ml}$ ) under argon, and to the suspension was added a THF solu- tion of $\square(0.05 \mathrm{mmol})$ at RT. Then imidazole $(3.4 \mathrm{mg}$, $0.05 \mathrm{mmol}$ ) was added, and the mixture was stirred at RT overnight. Toluene/triethylamine was also used as a solvent/base. After the solid was washed with toluene twice, it was dried up in vacuo. The catalyst was analyzed by high-resolution solid-state CP/MAS ${ }^{29} \mathrm{Si}$ NMR spectroscopy. The $\mathrm{Zr}$ content in the prepared catalysts was determined by ICP analysis. Reference catalysts were prepared similarly using complex $\square$ without base.

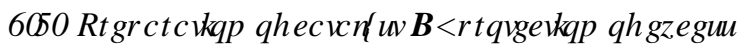 KI GR[। JLRXSVRQ UCFD WXUDFH}

Typically, to a suspension of silica gel $(0.5 \mathrm{~g})$ in toluene $(10 \mathrm{ml})$ was added a toluene solution of $\mathrm{Me}_{3} \mathrm{SiCl}(0.45 \mathrm{mmol})$ and triethylamine $(0.45 \mathrm{~mol})$, and the mixture was stirred at RT overnight. The solid was washed twice with toluene and dried in vacuo, and then used for the immobilization of $\mathrm{Q}$. The immobilization process was similarly conducted to that described for catalyst $\$$.

\section{पा 3 USDDWRQRI FDWDOWC DQG UHDUG UHAWRQV}

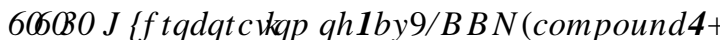

To a solution of $83.5 \mathrm{mg}(0.20 \mathrm{mmol})$ of $\quad$ in $5 \mathrm{ml}$ of toluene was added a hexane solution of 9-borabicyclo[3.3.1]nonane (9-BBN, $0.5 \mathrm{M}$, $0.30 \mathrm{mmol}$ ) and this mixture was stirred at $50^{\circ} \mathrm{C}$ overnight. After removal of the volatiles in vacuo, compound $\square$ remained as a colorless oil in nearly quantitative yield. ${ }^{1} \mathrm{H}$ NMR $\left(\mathrm{C}_{6} \mathrm{D}_{6}=7.16 \mathrm{ppm}\right)$ : $\delta=0.45(\mathrm{~s}, 3 \mathrm{H}), 1.1(\mathrm{~m}, 2 \mathrm{H}), 1.16-1.26(\mathrm{~m}, 2 \mathrm{H})$, $1.37-1.51\left(\mathrm{~m}, 2 \mathrm{H}, \mathrm{B}-\mathrm{C}+{ }_{2}\right), 1.58-1.91(\mathrm{~m}, 12 \mathrm{H})$, $1.90,1.92,2.25,2.29,5.10(\mathrm{~d}, J=2 \mathrm{~Hz}, 1 \mathrm{H}), 5.15$ $(\mathrm{d}, J=2 \mathrm{~Hz}, 1 \mathrm{H}), 6.33-6.40(\mathrm{~m}, 2 \mathrm{H}) .{ }^{13} \mathrm{C} \mathrm{NMR}$ $\left(\mathrm{C}_{6} \mathrm{D}_{6}=128.0 \mathrm{ppm}\right): \delta=-4.65\left(\& \mathrm{H}_{3}-\mathrm{Si}\right), 6.53$ $\left(\& \mathrm{H}_{2} \mathrm{Si}\right), 15.78,15.82,16.90,16.99(\mathrm{Cp} 0 \mathrm{H} \times 4)$, 18.89 (br, \& $\left.\mathrm{H}_{2}-\mathrm{B}\right), 23.55,31.52$ (br, B- $\left.\& \mathrm{H}\right), 33.57$, $103.44,103.81,112.60,113.46,127.86,128.88$, 129.56, 130.16, 137.63, 138.06.

Polymerization of propene using $\square$ was conducted in a autoclave. To a solution of $\square(10 \mu \mathrm{mol})$ in toluene $(30 \mathrm{ml})$ was added methylaluminoxane $(20 \mathrm{mmol}$ of $\mathrm{Al})$ at RT and the mixture was stirred for $20 \mathrm{~min}$. The solution was then exposed to propene ( $3 \mathrm{~atm}$ ) and was stirred at RT for 15 min. An exothermic reaction was 
quenched with acidic methanol. Polymer was collected as white powder and dried in vacuo. Yield $7.55 \mathrm{~g}$ (activity $1010 \mathrm{~kg} \mathrm{PP} / \mathrm{mol} \mathrm{Zrh}$ atm).

\section{पस⿴囗 3 USDDWRQRI FDWDOWC}

Calcined silica gel $(0.4 \mathrm{~g})$ was suspended in an ethanol solution of chlorodimethylvinylsilane $(0.11 \mathrm{ml}, 0.8 \mathrm{mmol})$ at RT and the mixture was stirred overnight. The solid was washed twice with ethanol and the volatiles were removed in vacuo thoroughly to afford the vinyl-coated silica gel. Meanwhile, to a THF solution $(1 \mathrm{ml})$ of $\square(16.7 \mathrm{mg}, 0.04 \mathrm{mmol})$ was added a large excess of borane-THF adduct (1 M THF solution, $0.4 \mathrm{mmol}$ ), and the mixture was stirred at RT overnight. The volatiles were removed in vacuo and the residue was dissolved in toluene $(6 \mathrm{ml})$. This solution was added to the vinyl-coated silica gel. The suspension was stirred for 3 days at RT, washed twice with toluene, and dried in vacuo. ICP analysis showed that $\mathrm{Zr}$ content was $0.34-0.37$ wt. $\%$.

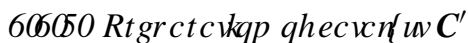

The "vinyl-coated" silica $(0.43 \mathrm{~g})$ prepared similarly to the described above was suspended in THF, and borane-THF adduct (1 M THF solution, $2.0 \mathrm{mmol}$ ) was added at RT. The mixture was stirred overnight. The solid was washed twice with THF, and the volatiles were removed in vacuo. To the suspension of the solid in toluene was added complex $\quad(17.7 \mathrm{mg}, 0.043 \mathrm{mmol})$ and the mixture was stirred overnight at RT. The solid was then rinsed twice with toluene and the solvent was removed in vacuo. ICP analysis showed that $\mathrm{Zr}$ content was 0.15 wt.\%.

\section{पए। 3RQP HUDWRQRI SURSHQH}

A typical procedure of polymerization of propene using the prepared catalysts is as follows. In a $100 \mathrm{ml}$ glass autoclave, the catalyst $(10 \mathrm{mg})$ was treated with MMAO (1.9 M toluene solution, $3.0 \mathrm{ml})$. After $10 \mathrm{~min}$, toluene $(27 \mathrm{ml})$ was added and the mixture was immersed in a water bath at $30^{\circ} \mathrm{C}$. Then propene was introduced, the mixture was stirred for $1 \mathrm{~h}$ and the pressure was kept at $3 \mathrm{~kg} / \mathrm{cm}^{2}$ during the reaction. The mixture was poured into acidic methanol to quench the reaction, the white powder was filtered and dried in vacuo at $70^{\circ} \mathrm{C}$ overnight. Molecular weight of the polymer and its distribution were measured by GPC analysis and the isotacticity was determined by ${ }^{13} \mathrm{C}$ NMR spectroscopy at $120^{\circ} \mathrm{C}$ in 1,2 -dichlorobenzene- $G$.

\section{\$ FNQRZ OGJH HQW}

The authors are grateful to Professor H.-H. Brintzinger for personal communication. Ms. Chieko Kariya is appreciated for ICP analyses. The authors thank Mr. Katsuo Yasumi (UBE Industry) for useful advice.

\section{HHHQFH}

[1] H.-H. Brintzinger, D. Fischer, R. Mülhaupt, B. Rieger, R.M. Waymouth, Angew. Chem. Int. Ed. Engl. 34 (1995) 1143.

[2] W. Kaminsky, J. Chem. Soc., Dalton Trans. (1998) 1413.

[3] K. Soga, T. Shiono, Prog. Polym. Sci. 22 (1997) 1503.

[4] G.G. Hlatky, Chem. Rev. 100 (2000) 1347.

[5] G. Fink, B. Steinmetz, J. Zechlin, C. Przybyla, B. Tesche, Chem. Rev. 100 (2000) 1377.

[6] N.V. Semikolenova, C.A. Zakharov, Macromol. Chem. Phys. 198 (1997) 2889.

[7] S.C. Hong, H.T. Ban, N. Kishi, T. Uozumi, K. Soga, Macromol. Chem. Phys. 199 (1998) 1393.

[8] T. Kitagawa, T. Uozumi, K. Soga, T. Takata, Polymer 38 (1997) 615.

[9] K. Soga, T. Arai, H. Nozawa, T. Uozumi, Macromol. Symp. 97 (1995) 53.

[10] H.G. Alt, P. Schertl, A. Köppl, J. Organomet. Chem. 568 (1998) 263.

[11] E.I. Iiskola, S. Timonen, T.T. Pakkanen, O. Härkki, P. Lehmus, J.V. Seppälä, Macromolecules 30 (1997) 2853.

[12] T. Arai, H.T. Ban, T. Uozumi, K. Soga, Macromol. Chem. Phys. 198 (1997) 229.

[13] K. Soga, H.T. Ban, T. Arai, T. Uozumi, Macromol. Chem. Phys. 198 (1997) 2779.

[14] D.-H. Lee, K.-B. Yoon, Macromol. Rapid Commun. 18 (1997) 427.

[15] B.Y. Lee, J.S. Oh, Macromolecules 33 (2000) 3194.

[16] B. Peifer, W. Milius, H.G. Alt, J. Organomet. Chem. 553 (1998) 205.

[17] H.G. Alt, M. Jung, J. Organomet. Chem. 562 (1998) 229.

[18] H.G. Alt, M. Jung, G. Kehr, J. Organomet. Chem. 562 (1998) 153.

[19] M. Aulbach, H.-F. Herrman, D. Bilda, C. Bingel, DE 19527 652 A1 (Hoechst, 1997).

[20] T. Huhn, N. Suzuki, Y. Yamaguchi, T. Mise, T. Chihara, Y. Wakatsuki, Chem. Lett. (1997) 1201. 
[21] N. Suzuki, H. Asami, T. Nakamura, T. Huhn, A. Fukuoka, M. Ichikawa, M. Saburi, Y. Wakatsuki, Chem. Lett. (1999) 341.

[22] C. Janiak, B. Rieger, Angew. Makromol. Chem. 215 (1994) 47.

[23] S.S. Sarma, S. Sivaram, Macromol. Chem. Phys. 198 (1997) 495.

[24] F. Quignard, C. Lecuyer, C. Bougault, F. Lefebvre,
A. Choplin, D. Olivier, J.-M. Basset, Inorg. Chem. 31 (1992) 928.

[25] B.L. Moroz, N.V. Semikolenova, A.V. Nosov, V.A. Zakharov, S. Nagy, N.J. O'Reilly, J. Mol. Catal. A: Chem. 130 (1998) 121.

[26] R. Anwander, I. Nagl, M. Widenmeyer, G. Engelhardt, O. Groeger, C. Palm, T. Röser, J. Phys. Chem. B 104 (2000) 3532. 